\title{
Heterodimers of Nanoparticles: Formation at a Liquid-Liquid Interface and Site-Specific Surface Modification by Functional Molecules
}

Hongwei Gu, Zhimou Yang, Jinhao Gao, C. K. Chang, Bing Xu*

\section{Supporting Information}

General: Oleylamine (97\%), oleic acid (99\%), hexadecane-1,2-diol(tech. 90\%), dioctyl ether(99\%), trioctylphosphine oxide(tech 90\%), hydrogen tetrachloroaurate (III) (99.9\%), and triethylamine (99\%) are purchased form Sigma-Aldrich, $\mathrm{Fe}(\mathrm{CO})_{5}$ and $\mathrm{Pt}(\mathrm{acac})_{2}(98 \%)$ from Strem Chem, and silver nitrate from Fisher Chemical. All the reactions were carried out under inert atmosphere unless otherwise stated.

Synthesis of $\mathrm{Fe}_{3} \mathrm{O}_{4}-\mathrm{Ag}(\mathbf{1})$ : $\mathrm{Fe}_{3} \mathrm{O}_{4}$ nanoparticles $(2 \mathrm{mg}$ ) were dissolved in $1 \mathrm{~mL}$ hexane, and mixed with the solution of silver nitrate $(2 \mathrm{~mL}, 1 \mathrm{mg} / \mathrm{mL})$ in a small vial. Brown emulsion was formed by ultrasonication. After reacting for 30 minutes (temperature of the vial: $\sim 50{ }^{\circ} \mathrm{C}$ ), the mixture was separated by centrifugation. $\mathrm{Fe}_{3} \mathrm{O}_{4}-\mathrm{Ag}$ heterodimer nanoparticles were formed in hexane.

Synthesis of FePt-Ag (2): FePt nanoparticles (2 mg) were dissolved in $1 \mathrm{~mL}$ hexane, and mixed with the solution of silver nitrate $(2 \mathrm{~mL}, 1 \mathrm{mg} / \mathrm{mL})$ in a small vial. Brown emulsion was formed by ultrasonication. After reacting for 15 minutes (temperature of the vial: $\sim 45^{\circ} \mathrm{C}$ ), the mixture was separated by centrifugation. FePt-Ag heterodimer nanoparticles were formed in hexane.

Synthesis of $A u-A g$ (3): Au nanoparticles ( $2 \mathrm{mg}$ ) were dissolved in $1 \mathrm{~mL}$ toluene, and mixed with the solution of silver nitrate $(2 \mathrm{~mL}, 1 \mathrm{mg} / \mathrm{ml})$ in a small vial. Pink emulsion was formed by ultrasonication. After reacting for 15 minutes (temperature of the vial: $\sim 45^{\circ} \mathrm{C}$ ), the mixture was separated via centrifugation. Au-Ag heterodimer nanoparticles were formed in toluene.

Synthesis of $\mathrm{Fe}_{3} \mathrm{O}_{4}-\mathrm{Au}(\boldsymbol{8}): \mathrm{Fe}_{3} \mathrm{O}_{4}$ nanoparticles $(2 \mathrm{mg}$ ) were dissolved in $1 \mathrm{~mL}$ hexane, and mixed with the solution of hydrogen tetrachloroaurate $(2 \mathrm{~mL}, 1.5 \mathrm{mg} / \mathrm{mL})$ in a small vial. Brown emulsion was formed by ultrasonication. After reacting for 30 minutes (temperature of the vial: $\sim 50{ }^{\circ} \mathrm{C}$ ), the mixture was separated by centrifugation. $\mathrm{Fe}_{3} \mathrm{O}_{4}$-Au heterodimer nanoparticles were formed in hexane.

Synthesis of 4: To a solution of thioacetylated $\omega$-mercaptocarboxylic acids $(0.1 \mathrm{mmol})$ and Nhydroxysuccinimide $(0.1 \mathrm{mmol})$ in $\mathrm{CHCl}_{3}(4 \mathrm{~mL}), 1,3$-dicyclohexylcarbodiimide $(0.11 \mathrm{mmol})$ was added at $0^{\circ} \mathrm{C}$. The reaction mixture was warmed up to room temperature. After stirring for 12 hours, the white precipitate was filtered. The solvent of the filtrate was removed under reduced pressure to afford thioacetylated $\omega$-mercaptocarboxylic acid $\mathrm{N}$-hydroxysuccinimide ester, which was utilized without further purification. This activated ester was immediately dissolved in $\mathrm{CHCl}_{3}(2 \mathrm{~mL})$, which was added by the $8 \mathrm{ml}$ methanol solution of 2-[12-(2-Amino-ethyl)-3, 8, 13, 18-tetramethyl-7, 17-dipentyl-22,24dihydro-porphin-2-yl]ethyl -amine ( 0.5 equiv, $0.07 \mathrm{mmol}$ ) and DIEA (2 equiv). The resulting reaction mixture was stirred at room temperature for 36 hours, then was concentrated and purified by flash chromatography $\left(\mathrm{CHCl}_{3} / \mathrm{MeOH}\right)$.

Synthesis of 5: Biotin (47 mg, $0.19 \mathrm{mmol})$ and 3-hydroxytyramine hydrochloride (40 mg, $0.21 \mathrm{mmol})$ were dissolved in $2 \mathrm{~mL}$ DMSO. After the mixture was degassed for three times and cooled to $0^{\circ} \mathrm{C}$, HBTU (91mg, 0.24mmol) and DIEA (excess) in $2 \mathrm{~mL}$ DMF was added under the protection of $\mathrm{N}_{2}$. The mixture was stirred for 30 hours under $\mathrm{N}_{2}$. Afterwards, the solution was dried, and the product was purified by HPLC.

Synthesis of 6: $\mathrm{Fe}_{3} \mathrm{O}_{4}-\mathrm{Ag}(2 \mathrm{mg})$ and $4(1 \mathrm{mg})$ were dissolved in $3 \mathrm{~mL}$ THF in a small vial and mixed by ultrasonication. After 30 minutes, a small magnet was applied to the wall of the vial to obtain the solid aggregates, which was purified by additional THF to get $\mathbf{6}$. 
Synthesis of 5- $\mathrm{Fe}_{3} \mathrm{O}_{4}-\mathrm{Ag}-4$ (7): $6(2 \mathrm{mg})$ and $5(3 \mathrm{mg})$ were dissolved in $3 \mathrm{~mL} \mathrm{MeOH}$. After mixed under ultrasonication for 30 minutes, a solid precipitates was acquired using a high-speed centrifuge. The solid of 7 was dissolved and kept in deionized water.

Synthesis of FITC-strepavidin-5-Fe $\mathrm{O}_{4}-\mathrm{Ag}-4$ (FITC-strepavidin-7): To the aqueous solution of 7, a FITC-streptavidin solution was added. After shaking for 15 minutes, a solid was acquired which was washed by DI water to offer FITC-strepavidin-7.

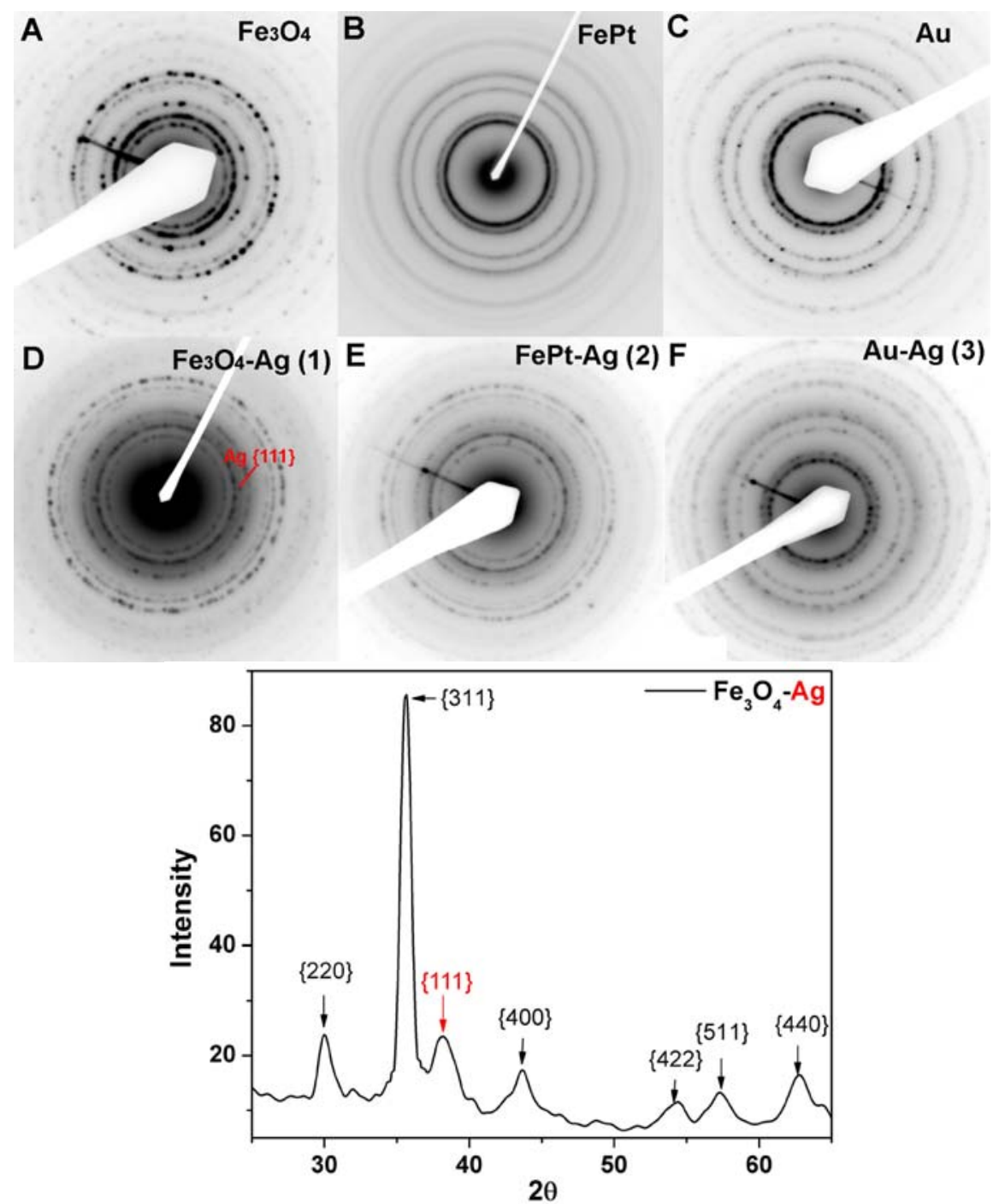

Figure S-1. EDP images of $\mathrm{Fe}_{3} \mathrm{O}_{4}, \mathrm{FePt}, \mathrm{Au}$ and 1, 2, 3 and $\mathrm{XRD}$ pattern of 1 .

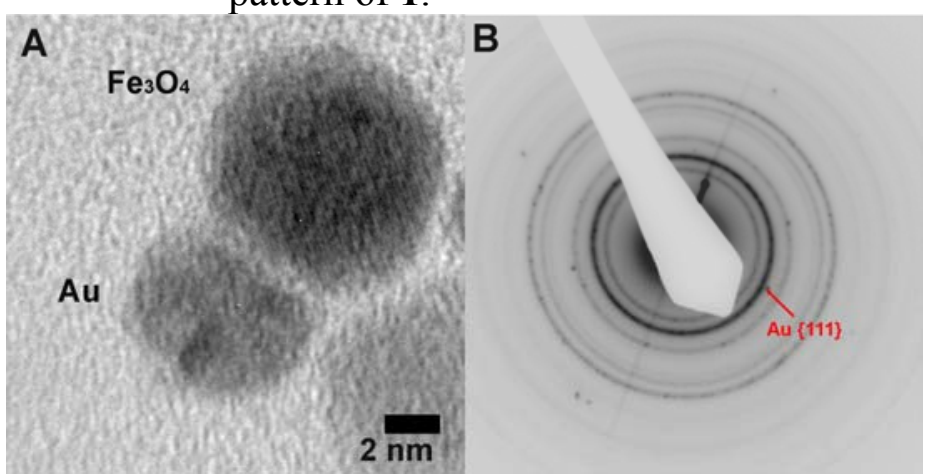

Figure S-2. (A) HRTEM and (B) EDP images of $\mathrm{Fe}_{3} \mathrm{O}_{4}-\mathrm{Au}(8)$. 

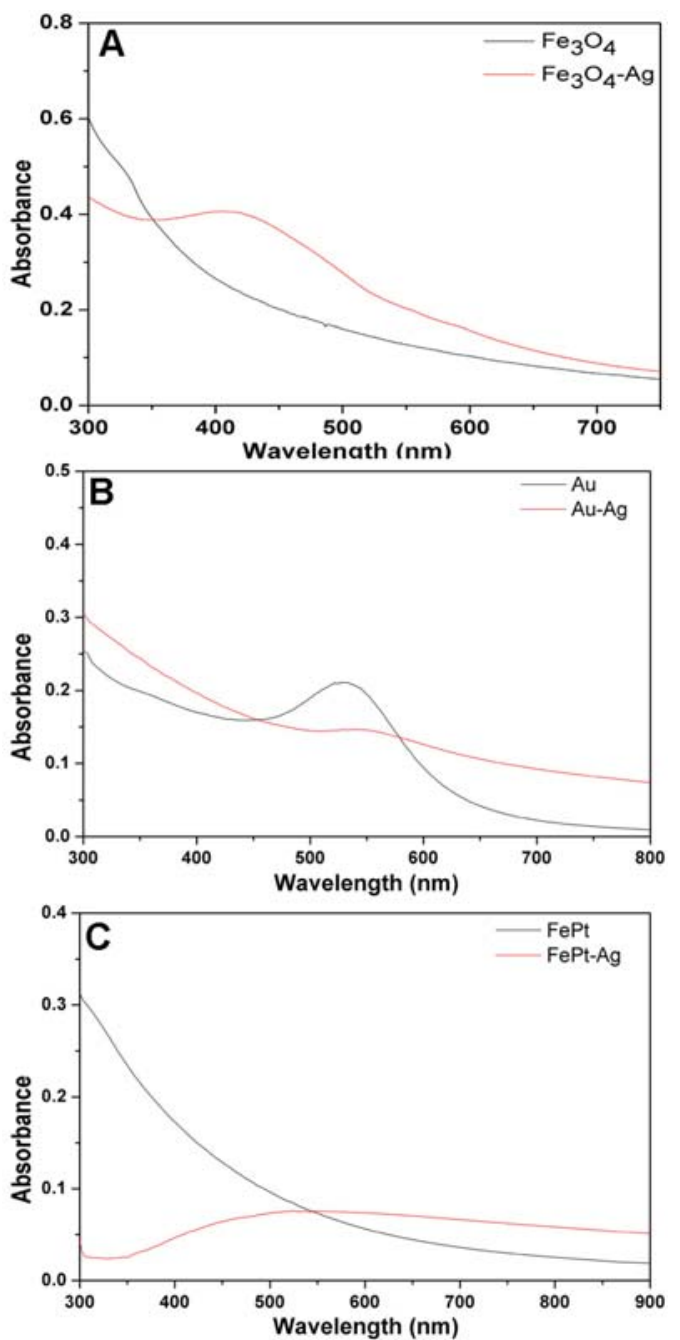

Figure S-3. UV-vis of $\mathrm{Fe}_{3} \mathrm{O}_{4}, \mathrm{FePt}, \mathrm{Au}$ and 1, 2, 3 .

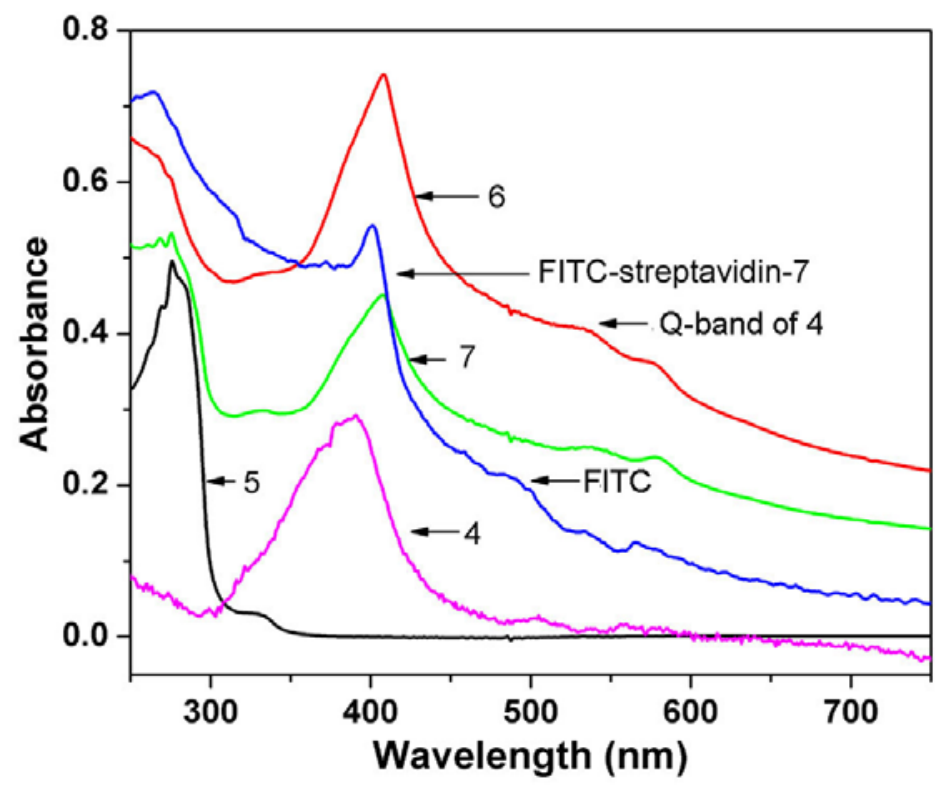

Figure S-4. UV-vis of 4, 5, 6, 7, and 7 binding to streptavidin-FITC. 


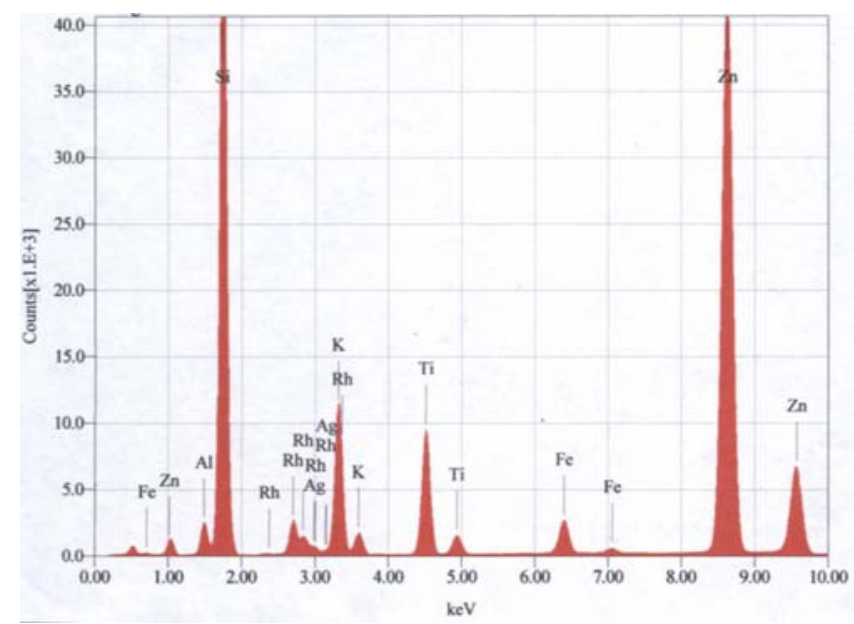

Figure S-5. XRF of $\mathrm{Fe}_{3} \mathrm{O}_{4}-\mathrm{Ag}$
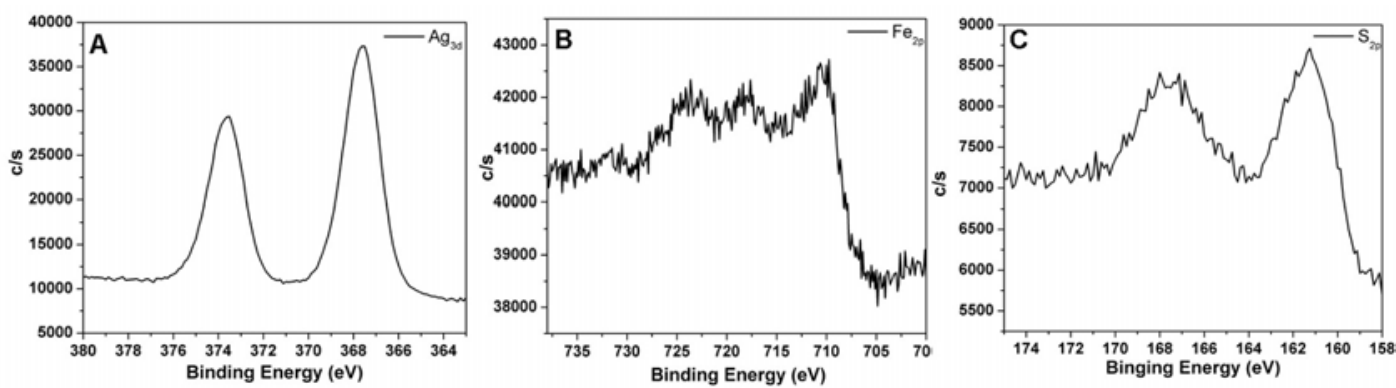

Figure S-6. XPS of 7
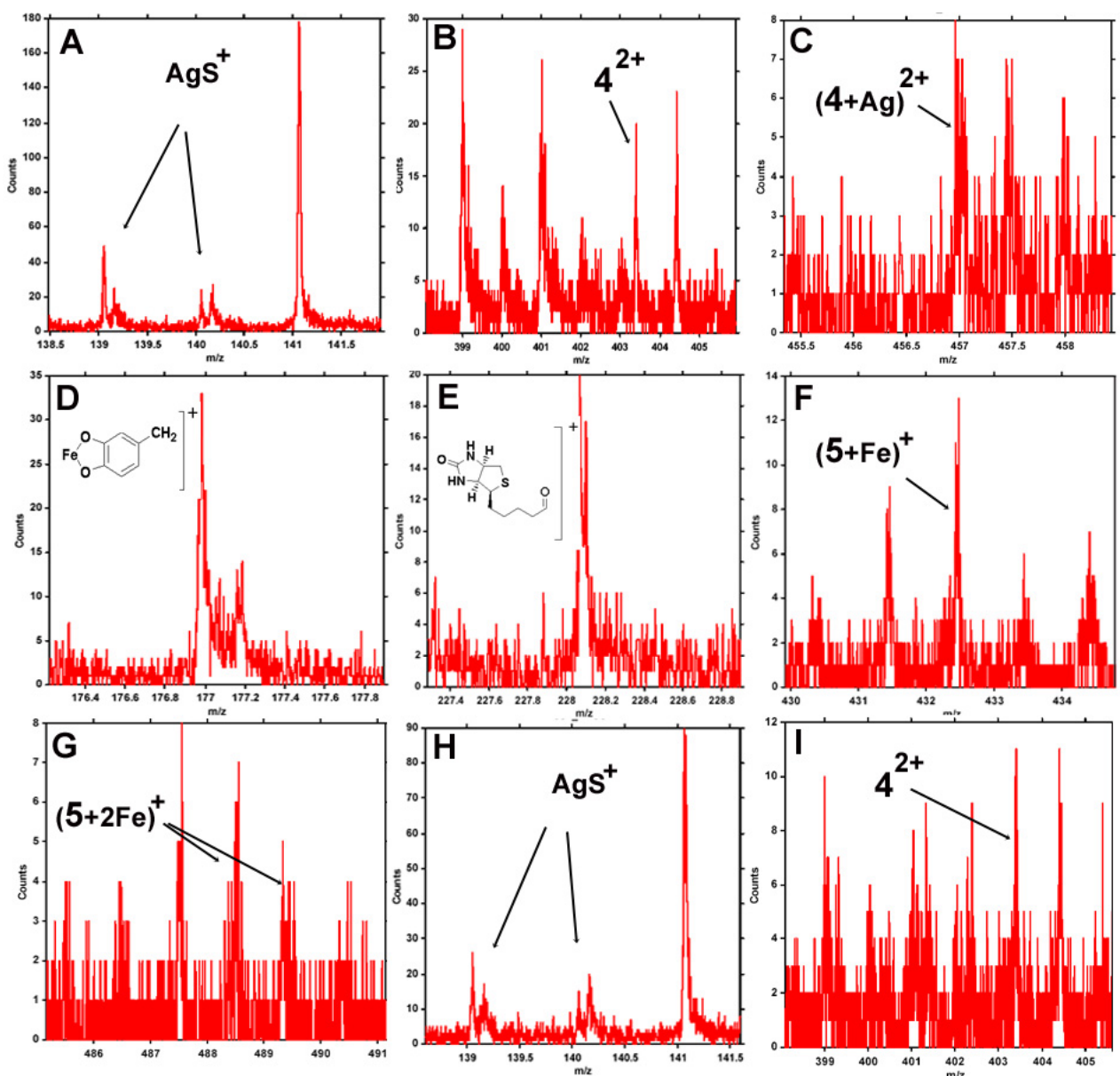

Figure S-7. ToF-SIMS of 6 (A, B, C) and 7 (D, E, F, G, H \& I) 
Estimation of the molecules on 7: According to XRF, which gives the molar ratio Fe:Ag=1.43:1, corresponding to the weight ratio $\mathrm{Fe}_{3} \mathrm{O}_{4}: \mathrm{Ag}=1.97: 1$, there are $4.06 \mathrm{mg}$ of $\mathrm{Fe}_{3} \mathrm{O}_{4}$ and $2.06 \mathrm{mg}$ of $\mathrm{Ag}$ in the $6.12 \mathrm{mg}$ of $\mathrm{Fe}_{3} \mathrm{O}_{4}-\mathrm{Ag}$ dimer. Since the diameter of $\mathrm{Ag}$ sphere is about $5 \mathrm{~nm}$, and the diameter of $\mathrm{Fe}_{3} \mathrm{O}_{4}$ sphere is about $8 \mathrm{~nm}$, the number of the heterodimers is $\sim 2.99 \mathrm{E} 15$. The weight of 4 is $2 \mathrm{E}-4 \mathrm{~g}$ before 4 reacts with 1 . After the reaction, the unreacted 4 is $0.92 \mathrm{E}-4 \mathrm{~g}$, according to UV-vis. Therefore, the number of 4 on 7 is $8.07 \mathrm{E} 16$, which affords $\sim 27$ molecules of 4 on 7 . The weight of 5 is $1 \mathrm{E}-2 \mathrm{~g}$ before 5 reacts with $\mathbf{6}$. After the reaction, the unreacted 5 is $5.9 \mathrm{E}-3 \mathrm{~g}$, according to UV-vis. Therefore, the number of $\mathbf{5}$ on $\mathbf{7}$ is $6.38 \mathrm{E} 18$, which affords $\sim 2135$ molecules of $\mathbf{5}$ on 7. 